\title{
JOB 13: EL DERECHO A LA DEFENSA
}

\section{La discusión central del libro de Job}

Pertenece al dinamismo de los procesos judiciales, especialmente en el mundo occidental contemporáneo, el deseo de hacer justicia pero respetando al mismo tiempo los derechos humanos. No obstante lo cual, se aceptan métodos de presión más o menos legítimos, o simplemente ilegítimos, desde la amenaza implícita, al acusado y/o a los jueces, pasando por el influjo de los medios de comunicación sobre la sociedad hasta el empleo de la violencia física, se llame presión física limitada o, más honestamente, tortura.

En muchos casos se trata de condenar al acusado dejando a la sociedad con la buena conciencia de haber cumplido estrictamente con las normas de justicia. La condena de un acusado que se declara inocente hasta el último momento, es siempre una espina irritante.

Los casos más aberrantes son aquellos en los cuales no se distingue más entre la presunta víctima, el acusador y el juez. En los procesos judiciales que siguen a acontecimientos militares (guerras, invasiones, deportaciones) se mezcla la fuerza del vencedor con la presión y los intereses políticos -cuando no económicos- para etiquetar como crímenes contra la humanidad acciones que también el vencedor ha cometido.

Solamente después de muchos decenios, cuando la mayoría de los primeros actores de los acontecimientos ha desaparecido, la sociedad se recupera lentamente de heridas profundas, que han tocado a culpables pero también a inocentes, a vencedores y vencidos, y se reconquista el derecho de apartarse de la historia oficial para evaluar los procesos ocurridos.

El libro de Job propone una pregunta que ha ocupado siempre a la raza humana desde que adquirió conciencia política y social: ¿cuál es la ley, 
el tribunal, el juez ante quien podemos ser legítima y honestamente juzgados, también por nosotros mismos?

En el estudio del libro de Job se ha concedido amplia atención a problemas teológicos y espirituales, como el sufrimiento del justo, y por consecuencia la relación entre el mal físico y la culpa ética; a la culpabilidad de Job, que no es evidente en ningún momento; a su dureza de corazón si era culpable; a la modesta teología en defensa de Dios de los amigos ${ }^{1}$ de Job, a la justicia del procedimiento divino de poner a prueba a Job, con diferentes males y dolores, y también a la presencia o ausencia de una conversión final de Job (pero, ¿por qué "conversión”, si no era culpable?).

Tal vez haya suscitado menos atención el problema que se encuentra en la base de todos los mencionados, es decir la presencia o ausencia de un procedimiento legítimo en el cual Job habría podido ser reconocido culpable o inocente, y condenado o liberado ${ }^{2}$.

En todo caso, el relato inicial del libro $(1,1-2,10)$ con el consejo divino y la decisión de tentar a Job para ver su reacción, la reacción misma de Job en esos capítulos y el epílogo en particular 42,7-17), son muy diversos de la larga discusión teológica como para ofrecer una clave de lectura de ella y una solución para los problemas abiertos. Tanto el relato inicial como el epílogo son una justificación biempensante de la tesis ampliamente aceptada y defendida por los amigos de Job, por los discursos de Elihu y por la respuesta final de Dios (Job 38-41) ${ }^{3}$.

Este estudio se concentra sobre un texto central del libro, que presenta elementos que nos permiten desarrollar nuestra hipótesis y ofrecer algunas reflexiones que pueden contribuir a la interpretación total.

1 Siguiendo la traducción habitual, hablo de sus "amigos" aunque se manifestarán más como gente cerrada en sí misma que como amigos, incapaces de un esfuerzo por comprender la angustia de Job. Tanto que, al final de la historia, merecen un castigo (Job 42,7-9).

Igualmente traduzco "Dios" cuando en el hebreo aparece Elohim (11 veces), Eloah (41 veces) o El (56 veces). El nombre del Dios de Israel, Yavé, aparece en Job solamente en los capítulos $1-2$ y 38, 40, 42, y excepcionalmente en 12,9 len total 22 veces).

${ }^{2}$ Más de una vez los estudiosos han expresado su pesimismo de poder llegar a una interpretación "definitiva" del libro de Job. Pero siempre se puede añadir algún punto de vista que enriquece la comprensión de este libro. Véase por ejemplo C. A. Newsom, The Book of Job: A Contest of Moral Imaginations, Oxford University Press, New York - 2009.

${ }^{3}$ No me parece posible reconciliar un Job místico que acepta su situación como un don divino con el Job que ocupa la mayor parte del libro, consciente de sus derechos de acusado, el tema al cual dedicamos este artículo. 
Se trata del capítulo 13, unido estrechamente a los capítulos que lo enmarcan, 12 y 14. Estos tres capítulos cierran en modo unitario el primer ciclo de los discursos de los amigos de Job. ${ }^{4}$

Aunque dos de los amigos, Elifaz y Bildad, habían recibido una primera respuesta de Job en los capítulos precedentes, el hecho de dirigirse a ellos en plural en 12,2-3 justifica considerar el texto como una respuesta de conjunto para los tres, si bien alguna referencia en segunda persona sugiere que Job tiene en mente el último discurso del tercer amigo, Zofar.

\section{Job 12 - La sabiduría y el poder divinos}

Job 12,2-11 es la respuesta de Job, por momentos con tono mordaz, a los discursos de sus amigos, que han presentado con solemnidad los argumentos habituales sobre la grandeza de Dios y la incomprensibilidad de sus decisiones: “ Realmente, ustedes son la voz del pueblo y junto con ustedes morirá la sabiduría!"5

Pero su verdadero pensamiento se añade en seguida (v. 3):

Pero yo también, como ustedes, soy capaz de entender, no estoy en nada por debajo de ustedes;

¿o acaso hay alguien que ignore estas cosas?

En el v. 4 Job recurre a su familiaridad con Dios para confirmar su conocimiento de aquellos principios fundamentales a los cuales han aludido sus amigos:

\section{śẹōq l'rēe 'ēhû 'ehyeh qōrēe' le’ĕlôa hạ wayya'ănēhû}

Me convertiría en motivo de burla para su (¿mi?) vecino,

si clamara a Dios para que me respondiera.

El versículo es ambiguo. No queda en claro si Job ha tomado la decisión de no preguntar nada para no convertirse en motivo de burla para los demás. Esto supondría que todos saben que Dios no responde, y por tanto es inútil clamar a él. Pero el versículo se puede interpretar positivamente,

${ }^{4}$ Una breve presentación de conjunto de los tres capítulos, con referencia particular a los comentarios de Clines, Habel y Hartley, ofrece D. J. Estes, Handbook on the Wisdom Books and Psalms, Baker Academic - Grand Rapids, MI - 2005, 63-70 (con bibliografía, casi exclusivamente en inglés). Sobre el libro de Job como totalidad véase C. A. Newsom,"The Book of Job", The New Intepreter's Bible led. L. E. Keck), Abingdom - Nashville - 1996, IV, 317-637.

${ }^{5}$ La traducción de los textos hebreos es de mi responsabilidad. He seguido alguna traducción (Biblia de Jerusalén en castellano, o Biblia de América) para los textos "no problemáticos". He traducido yo mismo los textos difíciles, a veces con una ligera paráfrasis para facilitar la comprensión del problema. 
como una pregunta perpleja y maravillada de Job: “¿Sería posible que me convirtiera en objeto de burla... solamente porque clamo a Dios para que me responda?" Las palabras finales del versículo, igualmente perplejas, parecen apoyar esta interpretación:

śe hִōq șāddî̀ tāmmîm.

¿objeto de burla, quien es justo y perfecto?,

retomando la caracterización de Noé $(\mathrm{Gn} 6,9)$.

Los vv. 7-8.13-15 pertenecen al argumento tradicional de la grandeza de Dios que la naturaleza (elementos y animales) testimonian. Pero el discurso adquiere interés particular y la afirmación se vuelve incisiva cuando se refiere al punto central de la discusión, el conocimiento concedido a los seres humanos:

Ante el infortunio, desprecio -dice el satisfecho-, un golpe más al que vacila!" (v. 5).

El sentido de la frase es: ustedes conocen todas las cosas obvias y que en el fondo no los tocan de cerca, por ejemplo, que Dios ha hecho el universo. Pero la capacidad de comprender el sufrimiento de los demás, ustedes que viven en la seguridad sin ninguna preocupación, ésta no la tienen.

Los vv. 12-13 son una pausa que introduce la segunda sección del capítulo: se contraponen la sabiduría y la inteligencia divinas a la de los "ancianos", mencionada también en Job 15,10; 29,8, de la cual pretenden participar sus amigos:

En los ancianos se encuentra la sabiduría, y en la larga vida la prudencia $(12,12)$.

Cuando se trata de Dios, sin embargo, a la sabiduría y prudencia se suma el "poder" y "el consejo", que se debería traducir "la capacidad de decisión".

¡En él se encuentran la sabiduría y el poder

a él pertenecen el "consejo" y la prudencia! $(12,13)$.

Desde el v. 14 y hasta el v. 25 se extiende la mención de los actos de inteligencia y poder atribuidos a Dios, que incluyen también el castigo de las capacidades intelectuales: confundir, golpear de locura a los jueces, quitar la autoridad a los sacerdotes y al rey.

Si Dios se manifestaba capaz de "arrancar a las tinieblas las cosas ocultas y de llevar a la luz lo que está envuelto en tinieblas de muerte" (v. 22), es también él quien quita el buen sentido (v. 24), de modo que los importantes personajes mencionados se tambalean en las tinieblas, sin ninguna luz, como borrachos (v. 25). 
El capítulo 12 como conjunto pone de relieve la sabiduría y poder de Dios. Sin embargo, esto no es una alabanza sino una imputación, como se manifestará en los capítulos 13 y 14. El capítulo 13 se centrará sobre el pedido implícito de Job de tener un proceso justo. El capítulo 14, por su parte, manifestará la impotencia y sufrimiento del hombre ante un Dios sabio y poderoso, que tendría tanto que hacer en el mundo, y en cambio se ocupa de los modestos crímenes de los seres humanos.

\section{Job 13 - La exigencia de un proceso justo}

Sobre el fondo del capítulo 12, el capítulo 13 se revela así mucho más dramático. Los primeros dos versículos son casi la conclusión del discurso precedente ("Todo lo que ustedes saben también yo lo sé", 13,2, cf. 12,3).

Job 13 se puede considerar organizado en tres secciones: en la primera (vv. 3-13) se expresa la impaciencia de Job ante los discursos de sus amigos. Los vv. 3 y 13 se contraponen de modo evidente: por una parte Job querría "hablar al Omnipotente", expresión repetida aún en el v. 13, "discutir con Dios". Su deseo se ve impedido por los discursos interminables de sus amigos y por eso Job debe vérselas primero con ellos, y rechazar sus discursos: "Oh, si ustedes hicieran silencio" (v. 5), "escuchen" (v. 6), "callen" (v. 13).

\subsection{Job rechaza a los "abogados de oficio" (Jb 13,3-13)}

Los discursos de los amigos de Job son caracterizados como "mentiras de enjalbegadores" (aludiendo a quien pone una capa de cal sobre una grieta para ocultarla, no para resolver la falla) y discursos de falsos médicos (v. 4). Las palabras de quienes quieren dar una buena impresión son solamente el revoque que no tiene ninguna consistencia, el diagnóstico o la receta del médico incompetente. Más en detalle aún, Job desarrolla una precisa denuncia y reproche contra ellos. El término utilizado (tôkahat, "reproche", v. 6) pertenece a la raíz ykh, que Job utilizaba en el v. 3 expresando su deseo de "discutir" con Dios, o tal vez, reprocharlo o acusarlo.

Job descubre la naturaleza de las mentiras de sus falsos amigos cuando los acusa de "favorecer a Dios" (Job 13,8.10). El sintagma hebreo nś') pānîm ("levantar el rostro de alguien") 6 o nkr pānîm (reconocer a alguien $)^{7}$ indica la preferencia por alguien en oposición a otros, aun cuando sean "los otros" los que tienen la razón o el derecho ${ }^{8}$.

\footnotetext{
${ }_{6}^{6}$ Cfr. H. Simian-Yofre, "פנים", TWAT, VI, 629-659.

${ }^{7}$ Véase p. ej. Dt 1,17; 10,17; 16,19; Job 13,10; 32,21; Pr 18,5; 24,23; 28,21; ML 2,9.

${ }^{8}$ La expresión designa también al "favorito" del rey, posición que le permite cualquier tipo de injusticia.
} 
La exhortación a los jueces de Dt 1,17 precisa que se debe escuchar al humilde y al grande sin temer a ninguno. Como Dios mismo, que no acepta sobornos (Dt 19,17), tampoco los jueces pueden aceptar regalos, que ciegan los ojos del sabio y corrompen las palabras del justo.

Pervertir el derecho, hacer diferencias personales y aceptar regalos son equivalentes en Dt 16,19. También Pr 18,5 se refiere a los jueces y los exhorta a no tener preferencias personales. De modo semejante se expresan $\operatorname{Pr} 24,23 ; 28,21$ como una máxima de los sabios, y Ml 2,9 como exhortación a los sacerdotes, siempre en el contexto de la aplicación de la Ley.

Con esta expresión ("favorecer") repetida en 13,8.10, Job entra en el fondo del problema. Si sus amigos, en su modo de argumentar, no respetan la imparcialidad debida a los contendientes en un proceso judicial, por un lado muestran su escepticismo de que Dios pudiera vencer en un proceso imparcial, por otro suponen que Dios aceptaría esta corrupción de la justicia en su propio beneficio y ocultan sus propios intereses al ponerse al servicio de una de las partes, pensando que tal vez justamente por eso, Dios les será favorable en el momento oportuno. Por eso Job concluye su réplica con una pregunta cortante:

¿Les gustaría si Dios los examinara ly se entiende: "como ustedes hacen conmigo"]? ¿Creen poder engañarlo como se engaña a un hombre? (Job 13,9).

La preocupación por "escrutar", "examinar”, "buscar” (verbo hqqr) es propia de las corrientes sapienciales ${ }^{9}$ y en particular del libro de Job ${ }^{10}$. La imposibilidad de escrutar los designios divinos es afirmada por los amigos de Job $(5,9 ; 11,7)$ y aceptada por el mismo Job $(9,10)$. Los amigos exhortan a Job a hacer el mismo camino de ellos $(5,27 ; 8,8)$.

La intervención de Elihu (Job 32-37) también menciona el verbo hqr ("escrutar", 32,1) y presenta a Dios como quien hace el mal y destruye a los poderosos sin ningún interrogatorio $(34,24)$. Esta declaración apoya -sin darse cuenta- la protesta de Job que, justamente, se lamenta por ser condenado sin interrogatorio. En 36,26, Elihu recurre al argumento de los amigos de Job: "Dios es grande y no podemos conocerlo, el número de sus años es incalculable" (usando el verbo ḥqr: es imposible "investigarlo").

${ }^{9}$ Sobre un total de 39 presencias en la Biblia Hebrea, pertenecen 13 a Job, 6 a los Proverbios y 4 a los Salmos. Las otras 16 se distribuyen entre 12 libros bíblicos. Una discusión detallada de la importancia del término a partir del Salmo 8 he presentado en "¿Qué es el hombre? El Salmo 8, una meditación de Génesis 1-2", Revista Bíblica 71/3-4 (2009) 181-191, del cual retomo aquí unas líneas.

${ }^{10}$ Job $5,9.27 ; 8,8 ; 9,10 ; 11,7 ; 13,9 ; 28,3.27 ; 29,16 ; 32,11 ; 34,24 ; 36,26 ; 38,16$. 
Si el Dios que presenta Elihu se escuda en su incomprensibilidad, Job mismo no tiene temor de ser escrutado porque se siente seguro de su inocencia.

A la luz de la importancia del concepto "indagar, escrutar, examinar" en el libro de Job, el discurso sobre la sabiduría (Job 28) considerado muchas veces como no perteneciente al texto de base ${ }^{11}$, tiene la precisa función de demostrar que es difícil acercarse a la Sabiduría. Los seres humanos pueden explorar las profundidades de la tierra para encontrar metales preciosos (vv. 1-4), pero la sabiduría y la comprensión de las cosas, ¿de dónde vienen? (vv. 12.20). La falta de respuesta a esta pregunta es un argumento a favor de la posición de Job. El ser humano no dispone del instrumento necesario para poder distinguir entre el bien y el mal, es decir de la sabiduría, "escondida a los ojos de todo viviente" (Job 28,21), encerrada en el inaccesible jardín del Génesis del cual el hombre nunca ha tenido la llave.

Frente a esta trágica consecuencia, las explicaciones que pueden ofrecer los amigos-enemigos de Job no son sino respuestas hechas de cenizas, fortalezas construidas de barro. En este momento, cuando ya ha dejado mudos a sus amigos (cf. Job 32), Job decide asumir su propia defensa, "suceda lo que suceda" $(13,13)$.

\subsection{Job prepara su defensa (Job 13,14-19)}

En los capítulos 6-7 y 9-10 del libro, las intervenciones de Job son sobre todo respuestas a sus amigos. Ha escuchado con paciencia, se ha lamentado de su situación y ha afirmado su inocencia. Solamente en algunos versículos se comenzaba a ver que no estaba dispuesto a aceptar humildemente una sentencia que consideraba injusta.

Ahora, en cambio, solamente quiere confrontarse con su acusador y juez. La decisión de asumir su propia defensa se expresa en dos frases de Job 13,14. La pregunta dramática "por qué debería tomar mi propia carne con los dientes" significa literalmente "por qué debería aniquilarme" o en todo caso: "¿por qué debería soportar, sin reaccionar, un proceso que considero inicuo?"

Job decide así no aceptar más los discursos de sus amigos, tal vez bienintencionados, y tampoco su situación actual, interpretada por ellos como un castigo, sino confrontarse objetivamente con los hechos, y "poner la vida en mis manos".

11 También por sus contactos con $\operatorname{Pr} 8,22-31$. 
Job no se ilusiona sobre sus posibilidades de obtener justicia. Considera su causa ya perdida ("él me eliminará, no espero ya nada", v. 15) ${ }^{12}$, pero ha decidido de todos modos hablar y defenderse. Su decisión de pedir la reapertura de su proceso podría, tal vez, producir algún efecto. Un impío, de hecho, no arriesgaría un nuevo juicio. Por eso, en Job 13,18 expresa su seguridad de ser reconocido inocente.

Como el servidor sufriente de Is 50,8 que desafiaba a sus acusadores (“cercano a mí está quien me defiende. Quién me podrá acusar") Job declara: “¿Hay alguno que pretenda acusarme?” (Job 13,19).

\subsection{Job exige un procedimiento legítimo (Job 13,20-29)}

Después de estas declaraciones preliminares, el lector esperaría una defensa de Job, que debería ser una apologia pro domo sua. Esta llegará solamente mucho más tarde, y concentrada en el capítulo 29, como descripción de su vida precedente, feliz, bajo la protección de un Dios benévolo.

En el capítulo 13, en cambio, no se trata propiamente de una defensa. Job pasa al ataque y presenta las verdaderas dificultades para someterse al proceso. Job requiere dos cosas: "ahórrame dos cosas" (Job 13,20).

El sentido de la primera es evidente: no ser amedrentado por la violencia divina. A esto se refiere su petición de "alejar de mí" tu mano y tus terrores (v. 21) ${ }^{13}$.

También en 9,34-35 Job suplica que Dios aleje de él su látigo y no lo asuste más, de modo que pueda hablar sin temor y demostrar su inocencia. ¿Cuál es, de hecho, la posibilidad de un acusado de defenderse, cuando está en una situación de sometimiento y sufrimiento y sabe que si su defensa no convence, empeorará su situación?

Es lógico pues, que en el mismo capítulo $(9,15)$ haya expresado su poca confianza en la justicia divina: "Aun si (yo) tuviera razón, no respondería, sino que imploraría misericordia a mi juez". Consciente de encontrarse frente a un juez arbitrario, Job está dispuesto a humillarse y pedir misericordia por crímenes no cometidos.

${ }^{12}$ Las dificultades del v. 15a (hēn yiq têelènîlō' [lô] 'ăyahēēl) son conocidas y dependen de leer lō', como el Ketib (negación “no", “I have no hope”, NRSV o "Je n'ai pas d'espoir", TOB) o bien leer lô, preposición con sufijo de tercera persona, con el Qere y traducir "en él esperaré". La opción por el sentido negativo parece más coherente con el carácter fuertemente dramático, decisivo, del versículo. Job, héroe trágico, se juega su vida antes Dios.

${ }^{13}$ De los terrores habla Job 20,$25 ; 33,7 ; 39,20 ; 41,6$. 
A su pedido de no aterrorizar al acusado pertenece también probablemente Job 13,25-27. La pregunta general “¿Quieres asustar a una hoja dispersa por el viento y dar la caza a una paja seca?" (v. 25) se articula inmediatamente en varias formulaciones, algunas que se deben interpretar literalmente, otras en sentido figurado. Dios impondría temor cuando como legislador prescribe una amarga sentencia por las culpas posibles (v. 26a); como verdugo pone el cepo en los pies del acusado (v. 27a), como juez instructor vigila todos los movimientos del presunto reo (ibid.) y como acusador recurre inclusive a las antiguas culpas juveniles (v. 26b).

La segunda exigencia se refiere en cambio al aspecto central del proceso: Job pide solamente saber cuál es el motivo de la imputación (vv. 22-23).

Entonces interrógame y responderé.

0 bien yo hablaré y tú responderás.

¿Cuántas son mis culpas y mis pecados?

Mis transgresiones, mis pecados, hazme conocer.

La pregunta de Job en el v. 23 se podría interpretar como una pregunta retórica, es decir como su declaración de que está seguro de su inocencia, y desafía a Dios a declarar sus presuntos pecados y a demostrar su culpabilidad.

Pero se puede leer también como la expresión perpleja y honesta del hombre que no comprende en qué consiste su culpabilidad.

Este Dios, capaz de sacar a la luz todo lo que está oculto, como establecía el capítulo 12, se rehúsa a exponer a Job sus culpas. Estamos aquí en el centro de la problemática de siempre: el ser humano tiene que cargar con sufrimientos cuya razón no comprende y con normas de cuya legitimidad no está convencido.

El pedido de Job del v. 23, "Hazme conocer... mi pecado", se expresa de otro modo en el v. 24: “¿Por qué escondes tu rostro?” (lāmmāh pānèkā tastîr). En el Sal 51 el orante pensaba saber cuáles eran sus pecados -“conozco mis culpas, mi pecado está siempre ante mí” (v. 5)- y suplicaba a Dios que escondiera (se cubriera) el rostro para no ver y no tener en cuenta sus culpas (hastēr pānèkā mēhată'āy, v. 11). Job, al contrario, reprocha a Dios que esconde su rostro. Solamente su presencia le permitiría conocer sus transgresiones ${ }^{14}$.

${ }^{14}$ El arrepentimiento final de Job 42,5-6 “Sólo de oídas te conocía, pero ahora te han visto mis ojos" podría significar una revelación "mística". Pero sería una respuesta modesta en proporción a la larga, minuciosa, dramática problemática del libro. 
Job considera la actitud divina como la de un padre o dictador que castigara sin escuchar y sin ofrecer explicaciones. El pedido de Job a su Dios no es escuchado, y sus culpas ni son declaradas, ni son admitidas por Job. El libro concluye sin explicarnos si Job era culpable de algo o no. Explícito en cambio es el deseo imperioso de hablar con Dios y su silencio como única respuesta.

\section{La duda radical de Job: culpabilidad humana y justicia divina}

Como no está en grado de demostrar su inocencia, porque no sabe de qué es acusado, en el capítulo 14 Job apela a otro argumento para convencer a Dios. Es una solución menor, no ya el recurso a la justicia divina ni tampoco al amor de Dios (del cual no se habla en el libro de Job ${ }^{15}$ ), sino solamente al buen sentido. Si los seres humanos están condenados a muerte y tienen los días contados (v. 5), ¿por qué no dejarlos en paz para que puedan gozar modestamente del tiempo de vida que les ha sido concedido?; un pensamiento sobre el cual vuelve Qohéelet en diferentes momentos (véase, un ejemplo por todos, Qo 9,9).

Job suplica, entonces $(14,6)$ :

Mira a otra parte y déjalo estar

para que pueda gozar de su día, como un jornalero.

Este pensamiento se apoya en una duda profunda sobre la justicia divina que Job 7,17-21 articula en cuatro preguntas: ¿qué es el hombre para que Dios tenga interés en castigarlo? ¿Hasta cuándo Dios continuará escrutándolo y poniéndolo a prueba? ¿Qué relación puede haber entre la trasgresión personal y la ofensa de Dios: "si he pecado, ¿qué (mal) te he hecho a ti ( $m \bar{a} h$ 'ep 'al lāk), guardián del hombre?’. Y en fin, ¿por qué Dios no está en grado de perdonar simplemente las transgresiones humanas, sin recurrir permanente al castigo?

El concepto "justicia", "ser justo" en sentido fuerte, aparece en el libro de Job al menos en cinco textos ${ }^{16}$. Elifaz en 4,17 y 15,14 ; el personaje Job en 9,2, Bildad en 25,4, y Dios mismo en 40,8 recurren a la contraposición entre la justicia divina y la justicia humana. La peculiaridad del uso en estos cinco textos se manifiesta en la formulación casi idéntica, consti-

${ }^{15}$ La raíz 'hb, “amar" aparece una sola vez, cuando Job recuerda a sus amigos que amaba.

${ }^{16} 24$ veces se usan 11 formas nominales o verbales de la raíz șdq, también en el sentido débil de "tener razón". 
tuida por una pregunta retórica encabezada por la partícula interrogativa $h \breve{a}$ o bien māh / ûmah / ha'ap que introduce el sujeto (el mortal, 'ĕnôš) del verbo "ser justo", siempre como preformativo de tercera persona (yișdāq), o de segunda ( $t i s \underline{d} \bar{a} q$ ) en la pregunta que Dios dirige a Job. Tres veces el verbo "ser justo" aparece en paralelo a "ser puro" (yithar / yizkeh) y en cuatro de estos cinco textos aparece un término de referencia ("más que Dios") o una contraposición (ser / declarar culpable).

Resumiendo, se trata de la pregunta "Cómo podría un ser humano ser justo ante Dios” o, cuando Dios interroga a Job $(40,8)$ : “Pretenderías eliminar mi juicio para justificarte?"

Ni Elifaz, ni Bildad, y tampoco Job, ponen en duda que sea imposible establecer una comparación entre la justicia divina y la justicia humana (en el sentido dicho de "ser justo"), no obstante Elihu lo acusaría de pensar que su justicia (la de Job) es superior a la de Dios $(32,2)$.

Los amigos de Job introducen la comparación no solamente en cuanto al "ser justo", sino también al "ser puro" ${ }^{17}$. Job se contenta con hablar del "ser justo". Hay aquí tal vez una voluntad de contraponer ambas posiciones. Los amigos de Job sienten que deben abajarse cuanto sea posible para dejar a Dios la exclusividad del ser justo. Job reconoce la superioridad del ser justo divino, pero sin renunciar a su posible participación en esta justicia.

La particular sensibilidad del libro de Job hacia este problema queda demostrada en el quinto texto, puesto en boca de Dios mismo (Job 40,8):

ha 'ap tāpēr mišpātî taršî‘ēnî l'ma'an tiṣdāq

¿Pretenderías eliminar mi juicio,

declararme culpable para justificarte?

La expresión lema'an tiṣdāq de Job 40,8 se encuentra en el AT solamente en Is 43,26 y en el Sal 51,6b.

El sentido en Is 43,26 es evidente. Yнwн contrapone su acción a favor de su pueblo a la actitud del pueblo mismo, que lo fastidia con sus exigencias e infidelidad, mientras él no lo ha cansado con sus pedidos. La exhortación "Despierta mi memoria, discutamos juntos, habla tú mismo para justificarte" es un ofrecimiento benévolo para dejar al acusado la posibilidad de declararse inocente. YHwh espera que el acusado pueda presentar algún atenuante de su culpabilidad.

${ }^{17}$ Los verbos thry zkh aparecen solamente dos veces cada uno en el libro de Job, y el primero de ellos solamente una vez en sentido ético. 
Completamente diferente es el contexto del Sal 51, en el cual el v. 6 causa perplejidad. El orante exclama primero, "He pecado contra ti, solamente contra ti; he hecho el mal ante tus ojos". Pero la dificultad llega en el v. $6 \mathrm{~b}$ :

lema an tiṣdāq be dobrekā tizkeh be šoptekā.

La dificultad es resuelta con traducciones como: "De modo que tú puedas manifestar tu justicia cuando hablas y seas intachable cuando juzgas". El paralelismo con Is 43,26 sugeriría en cambio: "De modo que tú puedas justificarte cuando juzgas..."

El contexto del Salmo es breve y difícil hasta hacer la frase incomprensible, y las traducciones se rigen por el sentido teológico tradicional. ¿Se quiere decir solamente que cuando el ser humano hace el mal, Dios puede (o debe) ejercitar su justicia? ¿O se quiere decir más bien que el ser humano debe reconocer el mal que ha hecho (o tal vez no ha hecho) para no empañar la justicia divina? Estamos aquí plenamente en el problema que introducía este artículo.

Job 40,8 es el texto más sutil y complicado de los tres que usan la expresión. Pertenece a la segunda respuesta de Dios a Job (Job 40,6-41,26), después de la primera respuesta (capítulos 38-39) y la transición (Job 40,1-5) hacia la segunda respuesta.

Ambas respuestas de Dios a Job coinciden en la sustancia como un elogio de Dios que enumera sus propias obras y capacidades y desafía a Job a hacer, saber o prever tanto como él puede hacerlo. La conclusión es que, finalmente, el hombre no puede comprender los caminos de Dios y por tanto tampoco la justicia de su obrar, y menos aún sus motivos para castigar a un ser humano.

Job 40,6 (segunda respuesta) comienza como 38,1 (primera respuesta) y coincide literalmente con Job 38,3. "Cíñete los muslos como un guerrero, te haré preguntas, y tú respóndeme". Esta segunda respuesta divina quiere evidentemente conectarse con la primera (Job 38,1 y siguientes) como una precisión teológica. El autor del libro de Job ha reconocido que no alcanzaba la primera respuesta, con su argumento del Dios creador, superior e incomprensible para convencer al personaje Job de una culpabilidad que él no comprendía. Era necesario afrontar la contraposición entre justicia divina y las pretensiones humanas. Por eso Jøb 40,8 incluye la difícil frase:

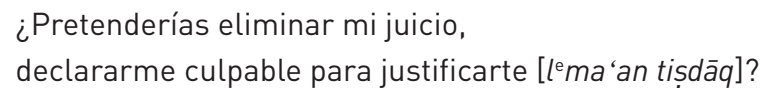

Esta respuesta refleja la inseguridad del autor de que haya casos donde la única posibilidad de absolver al ser humano sea la de condenar a 
Dios. Llegado a este punto no hay otra posible salida del dilema, sino la rebelión total o bien la fe ciega que acepta todo sin razonar más.

Se habla aquí de un verdadero conflicto. El ser justo de Dios y el ser justo del hombre parecen de tal modo contrastantes que no pueden coexistir. Si Job pudiera demostrar su inocencia, Dios sería culpable de haberlo perseguido. Pero si Job es culpable, ¿por qué Dios no lo declara explícitamente para que pueda arrepentirse? Y si, en todo caso, su culpa es congénita, como parte constitutiva de su naturaleza humana, ¿por qué acusarlo y condenarlo sobre la base de una naturaleza que él no ha elegido? ¿Cómo se podría hablar todavía de libertad y responsabilidad humana?

En Job 15,14 y 25,4, dos textos a los cuales hemos ya aludido, los amigos de Job se preguntan y le preguntan (como también se pregunta Sal 51,6b-7) cómo es posible que un ser humano "nacido de mujer" pueda ser puro e inocente ante Dios. ${ }^{18}$

Después de haberse asomado al abismo, el autor del libro da marcha atrás y hace recitar a Job una confesión final $(42,1-6)$ que retoma en el v. 4, como una súplica humilde, la misma expresión que Dios había pronunciado como un desafío en 40,7: "Te haré preguntas, y tú respóndeme".

Tal vez el autor del libro de Job ha encontrado un camino honorable para su atormentado poema teológico, pero ciertamente no ha encontrado una solución para el problema mismo; si tal solución existe. Queda como un punto adquirido pero conflictivo que solamente el reconocimiento del ser humano de su propio pecado restituye a Dios el derecho de afirmar su propia justicia. Dios sería el juez sensible que no puede dormir en paz cuando ha condenado un acusado que hasta el último momento ha reafirmado su inocencia.

$$
* * *
$$

La relación de la culpabilidad humana y la justicia no presenta un problema teórico cuando se trata de una ley humana claramente establecida. Quien ha transgredido la ley, es culpable. El problema puede estar solamente en la constatación del hecho, pero la relación entre el hecho y la ley está establecida por la misma definición de la ley.

El problema no se presenta tampoco en las relaciones con un dios concebido -como en la religión griega clásica ${ }^{19}$ - como un ser caprichoso,

18 También $\operatorname{Pr} 20,9$ concluye que nadie puede conservar un corazón puro y sin pecado. Al contrario, el Sal 119,9 afirma que quienes caminan en el camino del Señor pueden vivir una vida pura. Pero se trata de una tautología.

19 Pero no solamente en la tradición griega. Se recuerden los magníficos textos de Ludlul Bel Nemeqi (Alabaré al Señor de la Sabiduría), en particular la tablilla II, 
que establece justicia e injusticia según su gusto, y puede modificar la decisión cada vez que quiera. Lo que era justo puede volverse injusto y al contrario.

El problema, en fin, no se presenta en las concepciones éticas y humanistas que prescinden de la autoridad de un ser divino y establecen los criterios de bien y mal sobre la base de principios de convivencia social y de un general sentido de armonía con los seres humanos y el universo.

La relación entre culpabilidad humana y justicia divina se revela, en cambio, problemática en la fe del Antiguo y del Nuevo Testamento, porque se quiere afirmar la existencia de un Dios personal y justo, un compañero de camino del ser humano, que lo escucha y quiere respetar sus derechos, no de un Dios cruel y caprichoso.

El problema aparece menos grave o inexistente en los textos bíblicos en los cuales la composición literaria permite que un hombre hable con Dios, cara a cara, y se escuchen mutuamente.

Pero en otros textos bíblicos y en la vida de cada día del hombre común, el problema es agudo, porque el juicio divino llega trasmitido por testigos cuya garantía no es evidente, por textos que hay que interpretar, por instituciones y personas cuya propia autoridad, competencia, derecho de interpretar y justicia en el juzgar no es siempre indiscutible. Los amigos de Job encarnan estas personas e instituciones.

También el orante del Sal 51 parece más cercano a los amigos de Job que a Job mismo. Como ellos, el orante está dispuesto a aceptar su propia culpa; los amigos de Job aceptaban la culpa de éste como evidente, casi felices de reconocer su culpabilidad, de modo que se pudiera justificar la justicia divina.

Pero desde el fondo de tal posición emerge una imagen maligna de un dios que se alegraría de constatar culpas, para poder castigarlas (véase Sal 51,10.19).

Nuestra lectura de Job nos pone delante la sustancia del problema. El orante del Salmo 51 lo resuelve como el Job de 42,1-6, pero no como el autor de Job 40,8 que, no obstante la solución aparente propuesta, pone en plena luz el malestar que causa una concepción que apoya la justicia divina sobre la injusticia humana, y no alcanza a definirla sino como una capacidad punitiva.

líneas 32-37. Cf. mi presentación del texto en Sofferenza dell'uomo e silenzio di Dio nell'Antico Testamento e nella letteratura del Vicino Oriente Antico, Città Nuova Roma - 2005, 22-28. 
Parece que tanto el libro de Job como, en parte, el Salmo 51 se confrontan con una aplicación generalizada, dogmática e injusta del principio de que el sufrimiento físico presupone el pecado precedente. Ambos textos testimonian el conflicto interior de los autores bíblicos, que recurren a un principio establecido por la tradición religiosa de Israel, pero no alcanzan a expresar toda la amplitud del problema, en contradicción con la posición que querrían defender.

HORACIO SIMIAN-YOFRE

ROMA

h-simian-yofre@biblico.it 